\title{
Complete genome sequence of Acetohalobium arabaticum type strain $\left(Z-7288^{\top}\right)$
}

\author{
Johannes Sikorski ${ }^{1}$, Alla Lapidus ${ }^{2}$, Olga Chertkov ${ }^{3}$, Susan Lucas ${ }^{2}$, Alex Copeland ${ }^{2}$, Tijana \\ Glavina Del Rio ${ }^{2}$, Matt Nolan', Hope Tice ${ }^{2}$, Jan-Fang Cheng' ${ }^{2}$, Cliff $\mathrm{Han}^{2,3}$, Evelyne \\ Brambilla ${ }^{1}$, Sam Pitluck ${ }^{2}$, Konstantinos Liolios ${ }^{2}$, Natalia Ivanova ${ }^{2}$, Konstantinos Mavromatis ${ }^{2}$, \\ Natalia Mikhailova ${ }^{2}$, Amrita Pati ${ }^{2}$, David Bruce ${ }^{2,3}$, Chris Detter $^{3}$, Roxanne Tapia ${ }^{3}$, Lynne \\ Goodwin $^{2,3}$, Amy Chen ${ }^{4}$, Krishna Palaniappan ${ }^{4}$, Miriam Land ${ }^{2,5}$, Loren Hauser ${ }^{2,5}$, Yun-Juan \\ Chang ${ }^{2,5}$, Cynthia D. Jeffries ${ }^{2,5}$, Manfred Rohde ${ }^{6}$, Markus Göker ${ }^{1}$, Stefan Spring ${ }^{1}$, Tanja \\ Woyke $^{2}$, James Bristow ${ }^{2}$, Jonathan A. Eisen ${ }^{2,7}$, Victor Markowitz ${ }^{4}$, Philip Hugenholtz ${ }^{2}$, Nikos \\ C. Kyrpides ${ }^{2}$, and Hans-Peter Klenk ${ }^{{ }^{*}}$ \\ ${ }^{1}$ DSMZ - German Collection of Microorganisms and Cell Cultures GmbH, Braunschweig, \\ Germany \\ ${ }^{2}$ DOE Joint Genome Institute, Walnut Creek, California, USA \\ ${ }^{3}$ Los Alamos National Laboratory, Bioscience Division, Los Alamos, New Mexico, USA \\ ${ }^{4}$ Biological Data Management and Technology Center, Lawrence Berkeley National \\ Laboratory, Berkeley, California, USA \\ ${ }^{5}$ Oak Ridge National Laboratory, Oak Ridge, Tennessee, USA \\ ${ }^{6} \mathrm{HZI}$ - Helmholtz Centre for Infection Research, Braunschweig, Germany \\ ${ }^{7}$ University of California Davis Genome Center, Davis, California, USA \\ *Corresponding author: Hans-Peter Klenk
}

Keywords: anaerobe, mesophile, halophile, chemolithotroph, methylotroph, organotroph, degradation of betaine, consumption of trimethylamine, homoacetogen, Clostridia, Halanaerobiales, GEBA

Acetohalobium arabaticum Zhilina and Zavarzin 1990 is of special interest because of its physiology and its participation in the anaerobic $\mathrm{C}_{1}$-trophic chain in hypersaline environments. This is the first completed genome sequence of the family Halobacteroidaceae and only the second genome sequence in the order Halanaerobiales. The 2,469,596 bp long genome with its 2,353 protein-coding and 90 RNA genes is a part of the Genomic Encyclopedia of Bacteria and Archaea project.

\section{Introduction}

Strain Z-7288 (= DSM 5501 = ATCC 49924) is the type strain of the species Acetohalobium arabaticum, which is the type species of the genus Acetohalobium [1,2]. The genus name derives from the Latin word 'acetum', meaning vinegar, and the Greek words 'halos' and 'bios', meaning salt and life, respectively, in order to indicate an acetateproducing organism living in salt [3]. The species name derives from Arabat, a peninsula between the Sea of Azov and Sivash [3], since the strain was isolated from lagoons of the Arabat spit (East Crimea) which separates Sivash lake from the Sea of Azov [2]. Currently, this is the only known strain in the genus Acetohalobium. A. arabaticum partici- pates together with other halophilic bacteria and the genera Methanohalophilus and Methanohalobium in the $\mathrm{C}_{1}$-trophic chain in hypersaline environments [2]. Here we present a summary classification and a set of features for A. arabaticum Z$7288^{\mathrm{T}}$, together with the description of the complete genomic sequencing and annotation.

\section{Classification and features}

The cells of $A$. arabaticum are bent rods, motile by one to two subterminal flagella (Table 1) [2]. The flagella are stated in the original description [2], though they are not visible in our study (Figure 1). The cells are single, in pairs or form short chains, 
being 0.7-1 $\mu \mathrm{m}$ in diameter and 1-5 $\mu \mathrm{m}$ in length [2]. Other typical cell aggregates are palisades and ribbons, which are formed by adhesion of cells having intimate contact (Figure 1) [2]. The multiplication is by binary fission. The outer membrane is typical of a Gram-negative organism [2]. Growth is completely inhibited by $100 \mu \mathrm{M} / \mathrm{ml}$ streptomycin, benzylpenicillin, bacitracin, erythromycin, gentamycin, kanamycin, vancomycin or tetracyclin [2]. Strain Z-7288 ${ }^{\mathrm{T}}$ is obligately anaerobic, tolerating up to $12 \mathrm{mM} \mathrm{H}_{2} \mathrm{~S}$. Neither $\mathrm{O}_{2}, \mathrm{~S}_{2} \mathrm{O}_{3}{ }^{2-}, \mathrm{SO}_{4}{ }^{2-}$, nor $\mathrm{S}^{0}$ can serve as electron acceptors. Strain Z-7288 requires a salt concentration of $10-25 \% \mathrm{NaCl}$, the optimum is $15-18 \% \mathrm{NaCl}$ [2]. The optimal $\mathrm{pH}$ is between 7.6 and 8.0 [2].

A. arabaticum exhibits three modes of nutrition [2]: It is chemolithoautotrophic using $\mathrm{H}_{2}$ together with $\mathrm{CO}_{2}$ or $\mathrm{CO}$; it is methylotrophic using trimethylamine (TMA); and it is organotrophic using betaine, lactate, pyruvate or histidine. Carbohydrates are not utilized. No growth occurs on methanol, monomethylamine (MMA), dimethylamine (DMA), dimethylglycine, choline or sarcosine [2]. When grown on TMA, an equimolar amount of acetate is formed along with lesser amounts of DMA and MMA [2]. Betaine is degraded mainly to acetate and minor amounts of methylamines [2].

Carbonic anhydrase (CA; carbonate hydrolyase, EC 4.2.1.1) has been studied in strain $\mathrm{Z}-7288^{\mathrm{T}}$ and in other acetogenic bacteria [16]. This zinccontaining enzyme is found in animals, plants, bacteria and archaea and catalyzes the following reaction: $\mathrm{CO}_{2}+\mathrm{H}_{2} \mathrm{O} \leftrightarrow \mathrm{HCO}_{3}^{-}$and $\mathrm{H}^{+}$[16]. Further biochemical details of CA are described elsewhere [16]. Strain Z-7288 ${ }^{\mathrm{T}}$ displayed CA activities similar to those of other CA-containing bacteria [16-18]. With lactate as cultivation substrate the specific activity of CA in strain Z-7288 ${ }^{\mathrm{T}}$ has been determined to be $2.1 \pm 0.4$ units per mg or protein [16]. It has been suggested that one physiological function for CA in acetogens is to increase intracellular $\mathrm{CO}_{2}$ levels [16].

The 16S rRNA genes of the other type strains in the family Halobacteroidaceae share between 85.9\% (Orenia sivashensis [19]) and 95.1\% (Sporohalobacter lortetii [20]) sequence identity with

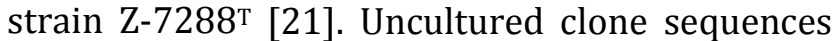
from environmental samples and metagenomic surveys do not surpass $84-86 \%$ sequence similarity to the $16 \mathrm{~S}$ rRNA gene sequence of strain Z$7288^{\mathrm{T}}$, indicating a lack of further members of the genus Acetohalobium in the habitats screened thus far (status June 2010).

Figure 2 shows the phylogenetic neighborhood of A. arabaticum $\mathrm{Z}-7288^{\mathrm{T}}$ in a $16 \mathrm{~S}$ rRNA based tree. The sequences of the five 16S rRNA gene copies in the genome of Acetohalobium arabaticum Z-7288 differ from each other by up to one nucleotide, and differ by up to three nucleotides from the previously published 16S rRNA sequence generated from DSM 5501 (X89077).

\section{Chemotaxonomy}

No chemotaxonomic data are currently available for the genus Acetohalobium.

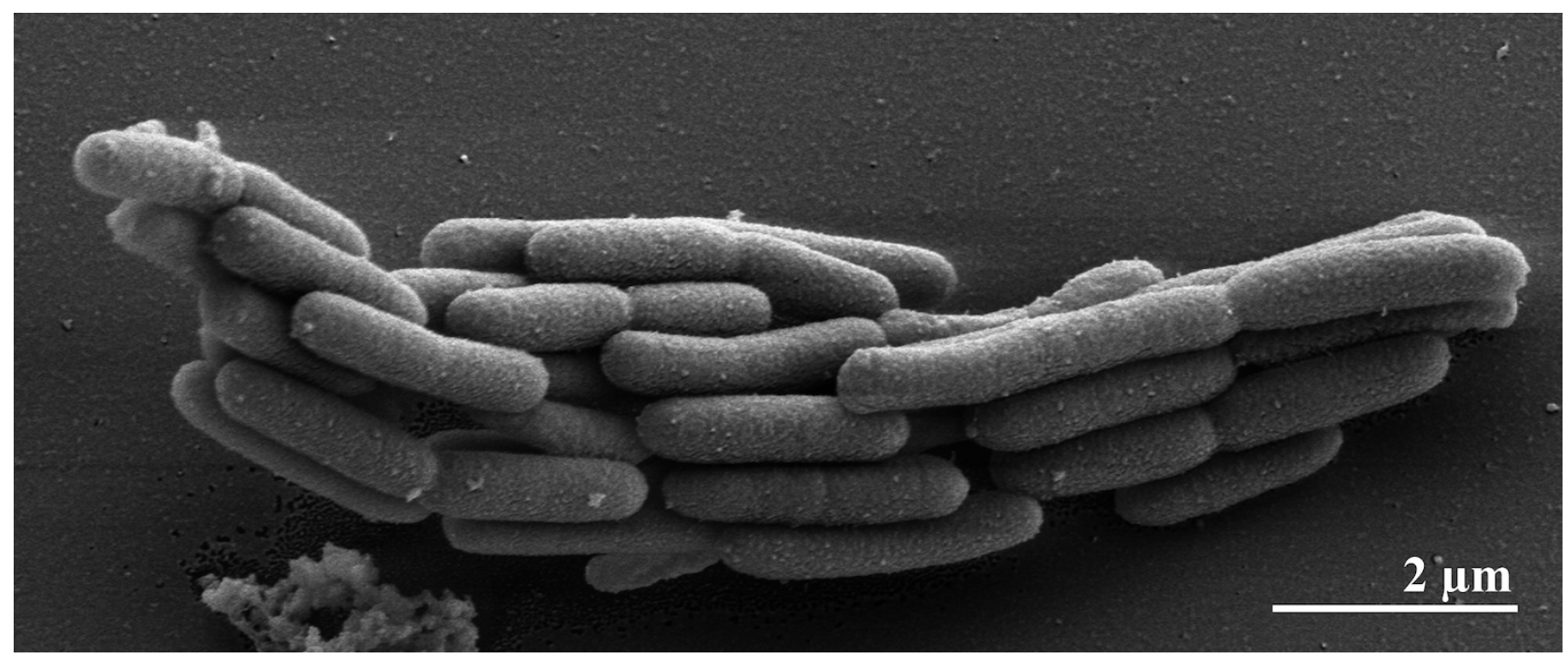

Figure 1. Scanning electron micrograph of $A$. arabaticum Z-7288 


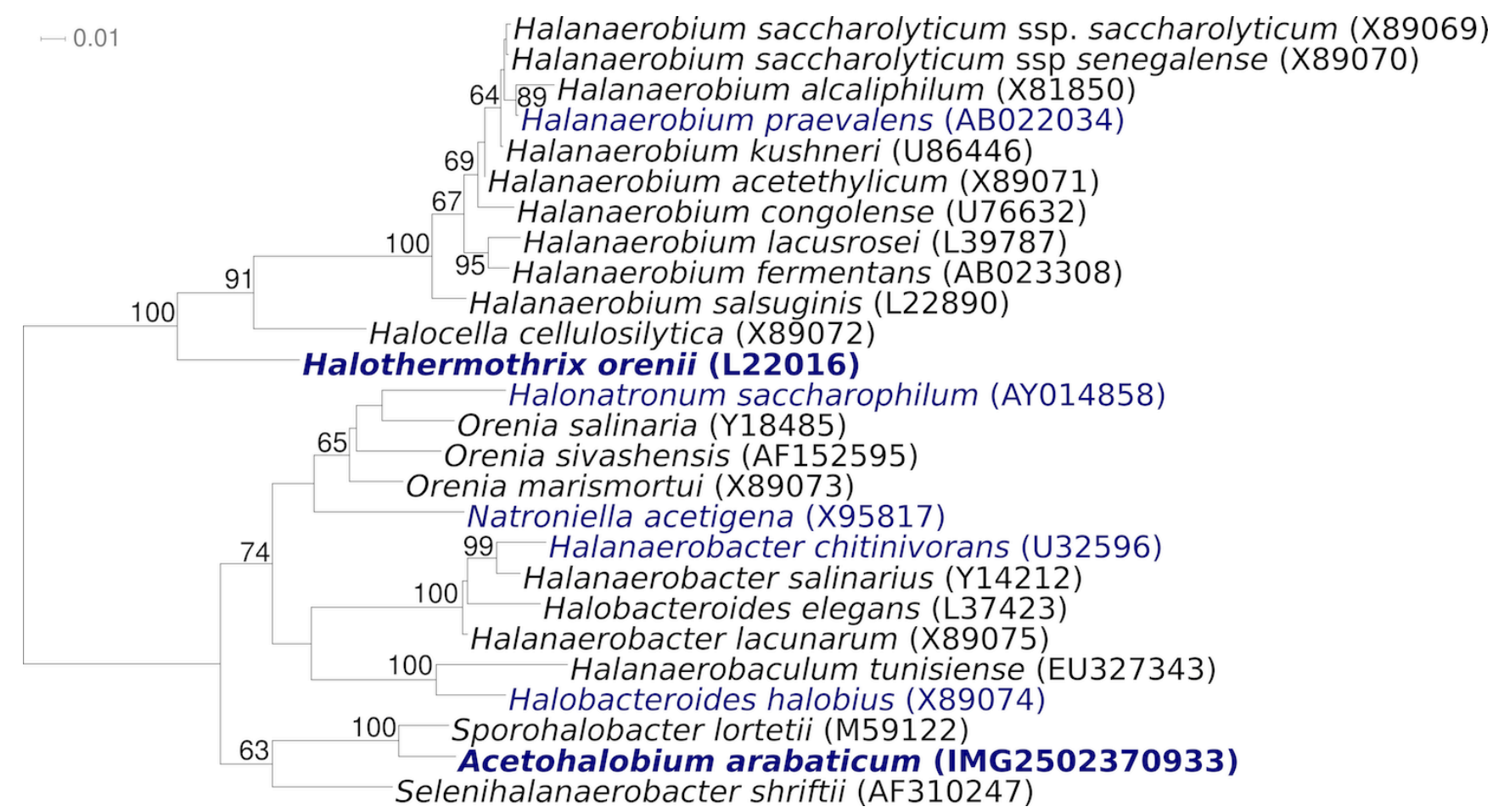

Figure 2. Phylogenetic tree highlighting the position of $A$. arabaticum Z- $7288^{\top}$ relative to the type strains of the other genera within the order Halanaerobiales. The trees were inferred from 1,308 aligned characters [22,23] of the $16 \mathrm{~S}$ rRNA gene sequence under the maximum likelihood criterion [24] and rooted in accordance with the current taxonomy [25]. The branches are scaled in terms of the expected number of substitutions per site. Numbers above branches are support values from 300 bootstrap replicates [26] if larger than 60\%. Lineages with type strain genome sequencing projects registered in GOLD [27] are shown in blue, published genomes [28] in bold.

\section{Genome sequencing and annotation} Genome project history

This organism was selected for sequencing on the basis of its phylogenetic position [29], and is part of the Genomic Encyclopedia of Bacteria and Archaea project [30]. The genome project is deposited in the Genome OnLine Database [27] and the complete genome sequence is deposited in GenBank. Sequencing, finishing and annotation were performed by the DOE Joint Genome Institute (JGI). A summary of the project information is shown in Table 2.

\section{Growth conditions and DNA isolation}

A. arabaticum Z-7288T, DSM 5501, was grown anaerobically in DSMZ medium 494 (Acetohalobium medium) [31] at $37^{\circ} \mathrm{C}$. DNA was isolated from $0.5-1 \mathrm{~g}$ of cell paste using MasterPure Gram Positive DNA Purification Kit (Epicentre MGP04100). Two $\mu l$ lysozyme and five $\mu$ mutanolysin were added to the standard lysis solution for
$40 \mathrm{~min}$ at $37^{\circ} \mathrm{C}$ followed by 1 hour incubation on ice after the MPC-step.

\section{Genome sequencing and assembly}

The genome of $A$. arabaticum $\mathrm{Z}-7288^{\mathrm{T}}$ was sequenced at using a combination of Illumina and 454 technologies. An Illumina GAii shotgun library with reads of $483 \mathrm{Mb}$ a 454 Titanium draft library with average read length of 341 bases, and a paired end 454 library with average insert size of $10 \mathrm{~kb}$ were generated for this genome. All general aspects of library construction and sequencing can be found at http://www.jgi.doe.gov/. Illumina sequencing data was assembled with VELVET and the consensus sequences were shredded into 1.5 $\mathrm{kb}$ overlapped fake reads and assembled together with the 454 data. Draft assemblies were based on $241 \mathrm{Mb} 454$ draft data, and 454 paired end data. Newbler parameters are -consed -a 50 -l 350 -g -m -ml 20. The initial assembly contained 72 contigs 
in one scaffold. The initial 454 assembly was converted into a phrap assembly by making fake reads from the consensus, collecting the read pairs in the 454 paired end library. The Phred/Phrap/Consed software package was used for sequence assembly and quality assessment in the following finishing process [32]. After the shotgun stage, reads were assembled with parallel phrap (High Performance Software, LLC). Possible mis-assemblies were corrected with gapResolution (http://www.jgi.doe.gov/), Dupfinisher [32], or sequencing cloned bridging PCR fragments with subcloning or transposon bombing (Epicentre Biotechnologies, Madison, WI). Gaps between contigs were closed by editing in Consed, by PCR and by Bubble PCR primer walks (J.-F. Cheng, unpublished). A total of 292 additional reactions were necessary to close gaps and to raise the quality of the finished sequence. Illumina reads were used to improve the final consensus quality using an inhouse developed tool (the Polisher [33], ). The completed genome sequences have an error rate of less than 1 in 100,000 bp.

Table 1. Classification and general features of A. arabaticum Z-7288 ${ }^{\top}$ according to the MIGS recommendations [4]

\begin{tabular}{|c|c|c|c|}
\hline MIGS ID & Property & Term & Evidence code \\
\hline & \multirow{8}{*}{ Current classification } & Domain Bacteria & TAS [5] \\
\hline & & Phylum Firmicutes & TAS $[6,7]$ \\
\hline & & Class Clostridia & TAS $[8,9]$ \\
\hline & & Order Halanaerobiales & TAS [10-12] \\
\hline & & Family Halobacteroidaceae & TAS $[11,12]$ \\
\hline & & Genus Acetohalobium & TAS $[1,13]$ \\
\hline & & Species Acetohalobium arabaticum & TAS $[1,13]$ \\
\hline & & Type strain Z-7288 & TAS [2] \\
\hline & Gram stain & negative & TAS [2] \\
\hline & Cell shape & bent rod & TAS [2] \\
\hline & Motility & motile, subterminal flagella & TAS [2] \\
\hline & Sporulation & unknown; not observed & NAS \\
\hline & Temperature range & $\max .47^{\circ} \mathrm{C}$ & TAS [2] \\
\hline & Optimum temperature & $28-40^{\circ} \mathrm{C}$ & TAS [2] \\
\hline & Salinity & $10-25 \%$ (optimal $15-18 \%$ ) $\mathrm{NaCl}$ & TAS [2] \\
\hline \multirow[t]{3}{*}{ MIGS-22 } & Oxygen requirement & anaerobic & TAS [2] \\
\hline & Carbon source & $\mathrm{CO}, \mathrm{CO}_{2}, \mathrm{TMA}$, betaine, lactate, pyruvate & TAS [2] \\
\hline & Energy source & chemolithoautotroph, methylotroph, organotroph & TAS [2] \\
\hline MIGS-6 & Habitat & lagoon & TAS [2] \\
\hline MIGS-15 & Biotic relationship & free-living & TAS [2] \\
\hline \multirow[t]{3}{*}{ MIGS-14 } & Pathogenicity & not reported & \\
\hline & Biosafety level & 1 & TAS [14] \\
\hline & Isolation & lagoon & TAS [2] \\
\hline MIGS-4 & Geographic location & Arabat Spit, Ukraine & TAS [2] \\
\hline MIGS-5 & Sample collection time & 1990 or before & TAS [2] \\
\hline MIGS-4.1 & Latitude & 46.26 & NAS \\
\hline MIGS-4.2 & Longitude & 34.86 & \\
\hline MIGS-4.3 & Depth & unknown & \\
\hline MIGS-4.4 & Altitude & about $15 \mathrm{~m}$ & NAS \\
\hline
\end{tabular}

Evidence codes - IDA: Inferred from Direct Assay (first time in publication); TAS: Traceable Author Statement (i.e., a direct report exists in the literature); NAS: Non-traceable Author Statement (i.e., not directly observed for the living, isolated sample, but based on a generally accepted property for the species, or anecdotal evidence). These evidence codes are from of the Gene Ontology project [15]. If the evidence code is IDA, then the property was directly observed by one of the authors or an expert mentioned in the acknowledgements. 
Table 2. Genome sequencing project information

\begin{tabular}{lll}
\hline MIGS ID & Property & Term \\
\hline MIGS-31 & Finishing quality & Finished \\
& Libraries used & $\begin{array}{l}\text { Two genomic libraries: 454 pyrosequence } \\
\text { standard and paired ended 10kb library }\end{array}$ \\
MIGS-28 & Sequencing platforms & 454 GS Titanium, Illumina GAii \\
MIGS-29 & Sequencing coverage & 98.4× pyrosequence \\
MIGS-31.2 & Newbler version 2.0.00.20- PostRelease- \\
MIGS-30 & Assemblers & 11-05-2008-gcc-3.4.6, phrap, Velvet \\
MIGS-32 & Gene calling method & Prodigal 1.4, GenePRIMP \\
& INSDC ID & CP002105 \\
& Genbank Date of Release & August 9, 2010 \\
& GOLD ID & Gc01329 \\
& NCBI project ID & 32769 \\
& Database: IMG-GEBA & 2502171194 \\
MIGS-13 & Source material identifier & DSM 5501 \\
& Project relevance & Tree of Life, GEBA \\
\hline
\end{tabular}

\section{Genome annotation}

Genes were identified using Prodigal [34] as part of the Oak Ridge National Laboratory genome annotation pipeline, followed by a round of manual curation using the JGI GenePRIMP pipeline [35]. The predicted CDSs were translated and used to search the National Center for Biotechnology Information (NCBI) nonredundant database, UniProt, TIGRFam, Pfam, PRIAM, KEGG, COG, and InterPro databases. Additional gene prediction analysis and functional annotation was performed within the Integrated Microbial Genomes - Expert Review (IMG-ER) platform [36].

\section{Genome properties}

The genome consists of a 2,469,596 bp long chromosome with a $36.6 \%$ GC content (Table 3 and Figure 3). Of the 2,443 genes predicted, 2,353 were protein-coding genes, and 90 RNAs; Seventyone pseudogenes were also identified. The majority of the protein-coding genes $(76.4 \%)$ were assigned a putative function while the remaining ones were annotated as hypothetical proteins. The distribution of genes into COGs functional categories is presented in Table 4.

Table 3. Genome Statistics

\begin{tabular}{lrr}
\hline Attribute & Value & \% of Total \\
\hline Genome size (bp) & $2,469,596$ & $100.00 \%$ \\
DNA coding region (bp) & $2,147,537$ & $86.96 \%$ \\
DNA G+C content (bp) & 904,645 & $36.63 \%$ \\
Number of replicons & 1 & \\
Extrachromosomal elements & 0 & \\
Total genes & 2,443 & $100.00 \%$ \\
RNA genes & 90 & $3.67 \%$ \\
rRNA operons & 5 & \\
Protein-coding genes & 2,353 & $96.33 \%$ \\
Pseudo genes & 71 & $3.30 \%$ \\
Genes with function prediction & 1,873 & $76.36 \%$ \\
Genes in paralog clusters & 505 & $20.58 \%$ \\
Genes assigned to COGs & 1,861 & $75.87 \%$ \\
Genes assigned Pfam domains & 2,022 & $82.43 \%$ \\
Genes with signal peptides & 378 & $15.41 \%$ \\
Genes with transmembrane helices & 303 & $12.35 \%$ \\
CRISPR repeats & 1 & \\
\hline
\end{tabular}




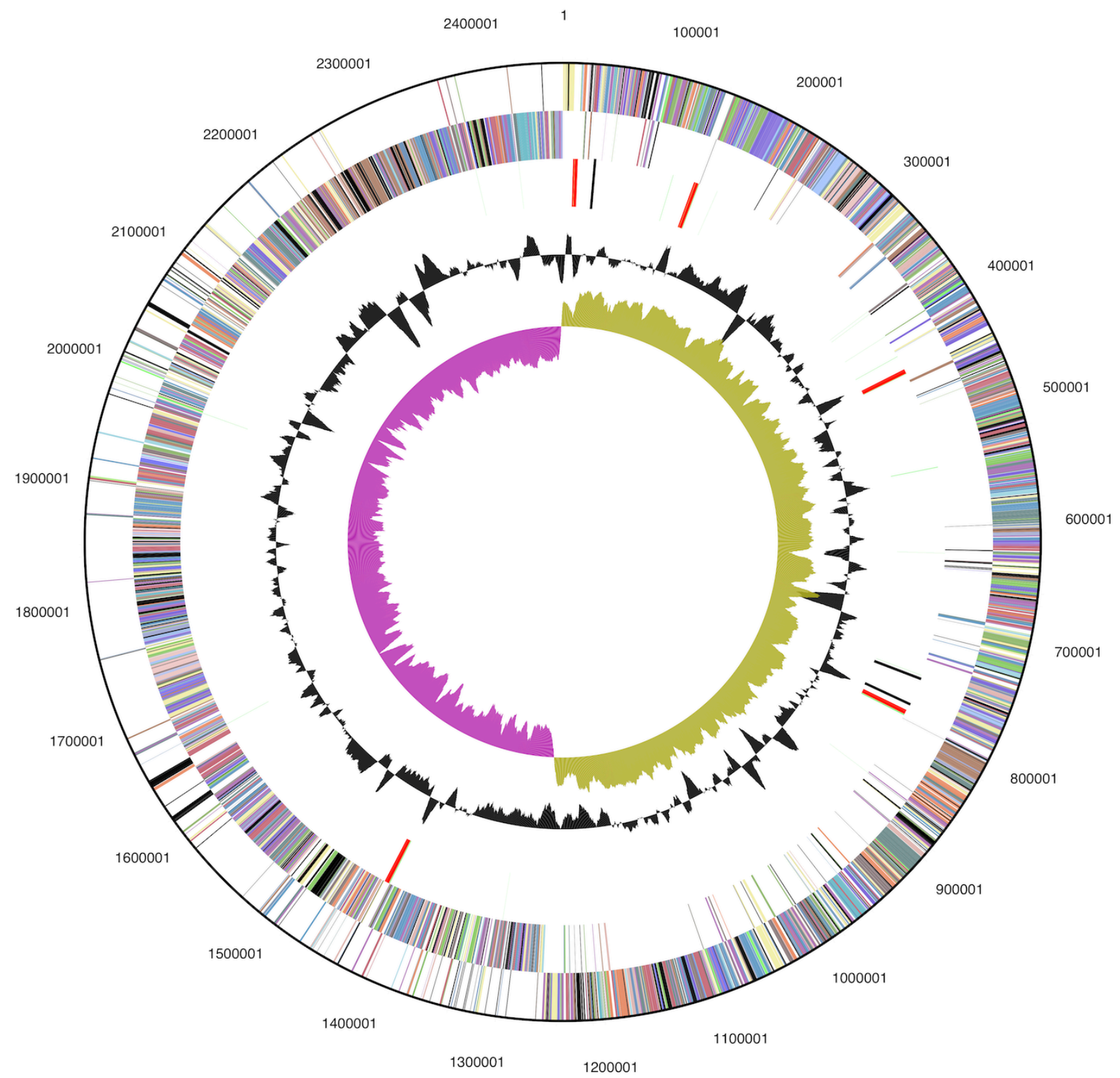

Figure 3. Graphical circular map of the genome. From outside to the center: Genes on forward strand (color by COG categories), Genes on reverse strand (color by COG categories), RNA genes (tRNAs green, rRNAs red, other RNAs black), GC content, GC skew.

Table 4. Number of genes associated with the general COG functional categories

\begin{tabular}{lrrl}
\hline Code & value & \%age & Description \\
\hline J & 133 & 6.5 & Translation, ribosomal structure and biogenesis \\
A & 0 & 0.0 & RNA processing and modification \\
K & 119 & 5.8 & Transcription \\
L & 139 & 6.8 & Replication, recombination and repair \\
B & 2 & 0.1 & Chromatin structure and dynamics \\
D & 26 & 1.3 & Cell cycle control, cell division, chromosome partitioning \\
Y & 0 & 0.0 & Nuclear structure \\
\hline
\end{tabular}


Table 4 (cont.) Number of genes associated with the general COG functional categories

\begin{tabular}{lrrl}
\hline Code & value & \%age & Description \\
\hline V & 21 & 1.0 & Defense mechanisms \\
T & 88 & 4.3 & Signal transduction mechanisms \\
M & 123 & 6.0 & Cell wall/membrane/envelope biogenesis \\
N & 66 & 3.2 & Cell motility \\
Z & 0 & 0.0 & Cytoskeleton \\
W & 0 & 0.0 & Extracellular structures \\
U & 56 & 2.8 & Intracellular trafficking, secretion, and vesicular transport \\
O & 85 & 4.2 & Posttranslational modification, protein turnover, chaperones \\
C & 150 & 7.4 & Energy production and conversion \\
G & 62 & 3.0 & Carbohydrate transport and metabolism \\
E & 187 & 9.2 & Amino acid transport and metabolism \\
F & 61 & 30 & Nucleotide transport and metabolism \\
H & 144 & 7.1 & Coenzyme transport and metabolism \\
I & 43 & 2.1 & Lipid transport and metabolism \\
P & 106 & 5.2 & Inorganic ion transport and metabolism \\
Q & 19 & 0.9 & Secondary metabolites biosynthesis, transport and catabolism \\
R & 224 & 11.0 & General function prediction only \\
S & 183 & 9.0 & Function unknown \\
- & 582 & 24.1 & Not in COGs \\
\hline
\end{tabular}

\section{Acknowledgements}

We would like to gratefully acknowledge the help of Maren Schröder (DSMZ) for growing cultures of $A$. arabaticum. This work was performed under the auspices of the US Department of Energy Office of Science, Biological and Environmental Research Program, and by the University of California, Lawrence Berkeley National Laboratory under contract No. DE-AC02-05CH11231,

\section{References}

1. Zhilina TN, Zavarzin GA. A new extremely halophilic homoacetogen bacteria Acetohalobium arabaticum, gen. nov. sp. nov. Dokl Akad Nauk SSSR 1990; 311:745-747.

2. Zhilina TN, Zavarzin GA. Extremely halophilic, methylotrophic, anaerobic bacteria. FEMS Microbiol Lett 1990; 87:315-322. doi:10.1111/j.15746968.1990.tb04930.x

3. Euzéby JP. List of bacterial names with standing in nomenclature: A folder available on the Internet. Int J Syst Bacteriol 1997; 47:590-592. PubMed doi:10.1099/00207713-47-2-590

4. Field D, Garrity G, Gray T, Morrison N, Selengut J, Sterk P, Tatusova T, Thomson N, Allen MJ, An-
Lawrence Livermore National Laboratory under Contract No. DE-AC52-07NA27344, and Los Alamos National Laboratory under contract No. DE-AC0206NA25396, UT-Battelle and Oak Ridge National Laboratory under contract DE-AC05-000R22725, as well as German Research Foundation (DFG) INST 599/1-2 and SI 1352/1-2.

giuoli SV, et al. The minimum information about a genome sequence (MIGS) specification. Nat Biotechnol 2008; 26:541-547. PubMed doi:10.1038/nbt1360

5. Woese CR, Kandler O, Wheelis ML. Towards a natural system of organisms: proposal for the domains Archaea, Bacteria, and Eucarya. Proc Natl Acad Sci USA 1990; 87:4576-4579. PubMed doi:10.1073/pnas.87.12.4576

6. Garrity GM, Holt JG. The Road Map to the Manual. In: Garrity GM, Boone DR, Castenholz RW (eds), Bergey's Manual of Systematic Bacteriology, Second Edition, Volume 1, Springer, New York, 2001, p. 119-169. 
7. Gibbons NE, Murray RGE. Proposals concerning the higher taxa of bacteria. Int I Syst Bacteriol 1978; 28:1-6. doi:10.1099/00207713-28-1-1

8. List editor. List of new names and new combinations previously effectively, but not validly, published. Int J Syst Evol Microbiol 2010; 60:469472. doi:10.1099/ijs.0.022855-0

9. Rainey FA. 2009. Class II. Clostridia class nov., p. 736. In P. De Vos, G. Garrity, D. Jones, N. R. Krieg, W. Ludwig, F. A. Rainey, K. H. Schleifer, and W. B. Whitman (ed.), Bergey's Manual of Systematic Bacteriology, 3 ed, vol. 3. Springer, New York.

10. Judicial Commission of the International Committee on Systematics of Prokaryotes. The nomenclatural types of the orders Acholeplasmatales, Halanaerobiales, Halobacteriales, Methanobacteriales, Methanococcales, Methanomicrobiales, Planctomycetales, Prochlorales, Sulfolobales, Thermococcales, Thermoproteales and Verrucomicrobiales are the genera Acholeplasma, Halanaerobium, Halobacterium, Methanobacterium, Methanococcus, Methanomicrobium, Planctomyces, Prochloron, Sulfolobus, Thermococcus, Thermoproteus and Verrucomicrobium, respectively. Opinion 79. Int J Syst Evol Microbiol 2005; 55:517-518. PubMed doi:10.1099/ijs.0.63548-0

11. Rainey FA, Zhilina TN, Boulygina ES, Stackebrandt E, Tourova TP, Zavarzin GA. The taxonomic status of the fermentative halophilic anaerobic bacteria: description of Haloanaerobiales ord. nov., Halobacteroidaceae fam. nov., Orenia gen. nov. and further taxonomic rearrangements at the genus and species level. Anaerobe 1995; 1:185-199. PubMed doi:10.1006/anae.1995.1018

12. List Editor. Validation of the publication of new names and new combinations previously effectively published outside the IJSB: List No. 55. Int J Syst Bacteriol 1995; 45:879-880. doi:10.1099/00207713-45-4-879

13. Validation of the Publication of New Names and New Combinations Previously Effectively Published Outside the IJSB. List No. 35. Int J Syst Bacteriol 1990; 40:470-471. doi:10.1099/00207713$\underline{40-4-470}$

14. Classification of bacteria and archaea in risk groups. www.baua.de TRBA 466.

15. Ashburner M, Ball CA, Blake JA, Botstein D, Butler $\mathrm{H}$, Cherry JM, Davis AP, Dolinski K, Dwight SS, Eppig JT, et al. Gene Ontology: tool for the unification of biology. Nat Genet 2000; 25:25-29. PubMed doi:10.1038/75556
16. Braus-Stromeyer SA, Schnappauf G, Braus GH, Gossner AS, Drake HL. Carbonic anhydrase in Acetobacterium woodii and other acetogenic bacteria. J Bacteriol 1997; 179:7197-7200. PubMed

17. Alber BE, Ferry JG. A carbonic anhydrase from the archaeon Methanosarcina thermophila. Proc Natl Acad Sci USA 1994; 91:6909-6913. PubMed doi:10.1073/pnas.91.15.6909

18. Karrasch M, Bott M, Thauer RK. Carbonic anhydrase activity in acetate grown Methanosarcina barkeri. Arch Microbiol 1989; 151:137-142. doi:10.1007/BF00414428

19. Zhilina TN, Turova TP, Kuznetsov BB, Kostrikina NA, Lysenko AM. Orenia sivashensis sp. nov., a new moderately halophilic anaerobic bacterium from Lake Sivash lagoons. Mikrobiologiya 1999; 68:519-527.

20. Oren A, Pohla H, Stackebrandt E. Transfer of Clostridium lortetii to a new genus Sporohalobacter gen. nov. as Sporohalobacter lortetii comb. nov. and description of Sporohalobacter marismortui sp. nov. Syst Appl Microbiol 1987; 9:239-246.

21. Chun J, Lee JH, Jung $Y$, Kim M, Kim S, Kim BK, Lim YW. EzTaxon: a web-based tool for the identification of prokaryotes based on $16 \mathrm{~S}$ ribosomal RNA gene sequences. Int / Syst Evol Microbiol 2007; 57:2259-2261. PubMed doi:10.1099/ijs.0.64915-0

22. Castresana J. Selection of conserved blocks from multiple alignments for their use in phylogenetic analysis. Mol Biol Evol 2000; 17:540-552. PubMed

23. Lee C, Grasso C, Sharlow MF. Multiple sequence alignment using partial order graphs. BioinformatiCs 2002; 18:452-464. PubMed doi:10.1093/bioinformatics/18.3.452

24. Stamatakis A, Hoover P, Rougemont J. A Rapid Bootstrap Algorithm for the RAxML Web Servers. Syst Biol 2008; 57:758-771. PubMed doi:10.1080/10635150802429642

25. Yarza P, Richter M, Peplies J, Euzeby J, Amann R, Schleifer KH, Ludwig W, Glöckner FO, RossellóMóra R. The All-Species Living Tree project: A $16 \mathrm{~S}$ rRNA-based phylogenetic tree of all sequenced type strains. Syst Appl Microbiol 2008; 31:241-250. PubMed doi:10.1016/j.syapm.2008.07.001

26. Pattengale ND, Alipour M, Bininda-Emonds ORP, Moret BME, Stamatakis A. How many bootstrap replicates are necessary? Lect Notes Comput Sci 
2009; 5541:184-200. doi:10.1007/978-3-642$\underline{02008-7 \_13}$

27. Liolios K, Chen IM, Mavromatis K, Tavernarakis N, Hugenholtz P, Markovitzz VM, Kyrpides NC. The Genomes On Line Database (GOLD) in 2009: status of genomic and metagenomic projects and their associated metadata. Nucleic Acids Res 2010; 38:D346-D354. PubMed doi:10.1093/nar/gkp848

28. Mavromatis K, Ivanova N, Anderson I, Lykidis A, Hooper SD, Sun H, Kunin V, Lapidus A, Hugenholtz P, Patel B, Kyrpides NC. Genome analysis of the anaerobic thermopholophilic bacterium Halothermothrix orenii. PLoS ONE 2009; 4:e4192. PubMed doi:10.1371/journal.pone.0004192

29. Klenk HP, Göker M. En route to a genome-based classification of Archaea and Bacteria? Syst Appl Microbiol 2010; 33:175-182. PubMed doi:10.1016/j.syapm.2010.03.003

30. Wu D, Hugenholtz P, Mavromatis K, Pukall R, Dalin E, Ivanova NN, Kunin V, Goodwin L, Wu $M$, Tindall BJ, et al. A phylogeny-driven genomic encyclopaedia of Bacteria and Archaea. Nature 2009; 462:1056-1060. PubMed doi:10.1038/nature08656
31. List of growth media used at DSMZ: http://www.dsmz.de/microorganisms/media_list.p $\underline{\mathrm{hp}}$

32. Sims D, Brettin T, Detter J, Han C, Lapidus A, Copeland A, Glavina Del Rio T, Nolan M, Chen F, Lucas $\mathrm{S}$, et al. Complete genome sequence of $\mathrm{Ky}$ tococcus sedentarius type strain $\left(541^{\top}\right)$. Stand Genomic Sci 2009; 1:12-20. doi:10.4056/sigs.761

33. Lapidus A, LaButti K, Foster B, Lowry S, Trong S, Goltsman E. POLISHER: An effective tool for using ultra short reads in microbial genome assembly and finishing. AGBT, Marco Island, FL, 2008

34. Hyatt D, Chen GL, Locascio PF, Land ML, Larimer FW, Hauser LJ. Prodigal Prokaryotic Dynamic Programming Genefinding Algorithm. BMC Bioinformatics 2010; 11:119. PubMed doi:10.1186/1471-2105-11-119

35. Pati A, Ivanova N, Mikhailova N, Ovchinikova G, Hooper SD, Lykidis A, Kyrpides NC. GenePRIMP: A gene prediction improvement pipeline for microbial genomes. Nat Methods 2010; 7:455-457. PubMed doi:10.1038/nmeth.1457

36. Markowitz VM, Ivanova NN, Chen IMA, Chu K, Kyrpides NC. IMG ER: a system for microbial genome annotation expert review and curation. Bioinformatics 2009; 25:2271-2278. PubMed doi:10.1093/bioinformatics/btp393 